\title{
Rhétorique de la publicité dans le français contemporain
}

\section{Pierre Brouland*}

L'omniprésence de la publicité est une des caractéristiques de nos sociétés contemporaines. On a pu évaluer qu'en moyenne, un Français était confronté chaque semaine à plus de 500 messages publicitaires. C'est dire à quel point la publicité est devenue un véhicule important de la langue, qu'elle soit écrite ou parlée. Parler d'une langue de la publicité reste cependant paradoxal. Car la publicité par nature est protéiforme. Son objectif est d'influencer un client potentiel, auquel elle empruntera son registre de langue : elle sera snob avec les snobs, «branchée » avec les jeunes, compassée avec les bourgeois, « canaille chic » avec les « bobos », et ainsi de suite. Cette capacité qu'a la publicité de recycler tous les thèmes et stéréotypes à la mode marque aussi ses limites et la condamne au conformisme.

Depuis la fin des années 1980, cependant, une nouvelle tendance est apparue avec la mondialisation. Les grandes marques multinationales choisissent de mener de plus en plus souvent des campagnes « universelles » en utilisant l'anglais, ou plus exactement un nombre limité de mots ou d'expressions issus de cette langue. Même si en France les pouvoirs publics se sont émus de cette situation et ont fait adopter en août 1994 une loi rendant obligatoire l'emploi du français pour « toute inscription ou annonce destinée à l'information du public », le phénomène semble inéluctable et la loi précitée s'avère régulièrement violée. On voit ainsi se développer dans la publicité une sorte de sabir, au lexique limité à une centaine de mots, dont certains comme « fun », « hot» ou « cool» finissent par contaminer la langue courante. La publicité deviendrait de la sorte le principal vecteur d'une certaine déliquescence du bien parler et favoriserait un relâchement général de la langue en multipliant les entorses à la syntaxe - par exemple, en faisant systématiquement fi de la double négation.

Si la publicité est souvent perçue comme un facteur d'appauvrissement de la langue, voire comme une véritable " anticulture », elle peut néanmoins être aussi étudiée sous l'angle de la rhétorique. En 1970 déjà, Jacques Durand dans un article de « Communications », la revue fondée et dirigée par Roland Barthes, avait établi un intéressant parallèle entre la rhétorique et la publicité. Il notait que le discrédit dans lequel est tenu la publicité dans le monde intellectuel vient pour partie du rejet de la rhétorique qui caractérise la pensée occidentale depuis l'époque romantique. Pour Durand, les publicitaires auraient, en quelque sorte, réinventé la rhétorique au XXe siècle ou plus exactement, ils auraient reconstitué sans le savoir, la plupart des figures de la rhétorique classique. Finalement, la publicité n'aurait donc pas inventé de nouvelles formes de persuasion. Bernard Brochand et Jacques Lendrevie, dans «Le Publicitor », publié en 1989, vont encore plus loin. Pour eux, les trois opérations de la rhétorique classique, l'inventio, la dispositio et l'elocutio se retrouvent dans la démarche publicitaire : à l'inventio correspond l'étude de marché ; à la dispositio, la « copy stratégie » et à l'elocutio, la conception et la rédaction du message.

En fait, la publicité n'utilise qu'un nombre limité de figures de style. La rédaction d'un slogan publicitaire doit satisfaire, en effet, un certains nombre d'exigences : concision, choix des mots en fonction de leur sonorité ou de leur pouvoir évocateur, ton humoristique.

* Pierre Brouland; Katedra románských jazyků, Fakulta mezinárodních vztahů, Vysoká škola ekonomická v Praze. 
Ces exigences éliminent de facto certaines tournures de style, en particulier celles qui expriment la passion. La tradition divise les figures de rhétoriques en trois catégories : les figures de mots qui tournent le sens propres des mots en un nouveau sens ou jouent sur les sonorités d'un mot, les figures de construction qui changent la construction grammaticale et les figures de pensée qui relèvent le sens ou la construction des mots par une tournure plus expressive de la pensée telle l'antithèse. D'autres classifications ont été proposées, notamment par Roland Barthes qui distinguaient ainsi les métaboles qui jouent sur la substitution d'un signifiant à un autre et qui se situent au niveau du paradigme, et les parataxes qui modifient les rapports entre signes successifs et qui se situent au niveau du syntagme. Nous conserverons cependant la classification traditionnelle, non pas que nous lui attribuons une valeur objective, mais parce qu'elle se plie aux commodités de l'analyse.

\section{A - Les figures de mots :}

\section{a) Figures jouant sur le sens des mots}

1 - La comparaison : La comparaison consiste à mettre en parallèle deux termes pour insister sur les rapport d'analogie qu'ils entretiennent entre eux, généralement à l'aide d'un comparant dont les plus usules sont comme, tel que ou semblable à. La comparaison est assez rarement utilisée dans les slogans publicitaires.

Contempler une Lancia Infini sans la conduire, c'est comme admirer une bouteille de Dom Perignon sans l'ouvrir

2-La métaphore: La métaphore consiste à changer le sens propre d'un mot en un sens figuré qui ne lui convient qu'en vertu d'une comparaison sous-entendue. En publicité, l'emploi de la métaphore est cependant risqué. Il convient d'éviter de glisser dans le cliché et la banalité ou, au contraire, de tomber dans l'énigmatique et l'obscur.

Mettez un tigre dans votre moteur [Publicité pour un carburant]

3 - La métonymie : La métonymie consiste à attribuer le nom d'un objet à un autre objet en vertu d'un rapport constant, par exemple le contenu pour le contenant, l'effet pour la cause, le signe pour la chose signifiée, etc.

Bergerac, des vins qui ont du nez [Le nez a le sens d'arôme, mais fait référence aussi à Cyrano de Bergerac]

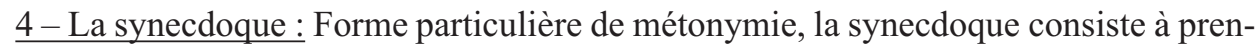
dre une partie pour le tout ou réciproquement.

Des millions de dents l'ont choisi [Publicité pour une marque de bonbons]

5-L'antanaclase: Un même mot est utilisé dans deux sens différents.

La Bretagne : les bains de mer pas les bains de foule - Les commerçants de mon quartier savent être commerçants [Sous la forme apparente d'une tautologie, cette publicité joue habilement sur le sens dérivé de l'adjectif commerçant, à savoir, qui sait comment attirer et satisfaire le client]

6-L'oxymore: L'oxymore consiste à rapprocher des mots en contrariétés pour réer une expression paradoxale.

La douce violence d'un parfum d'homme - De la part de ton ignoble chéri

7-L'hyponomie: Sans être à proprement parler une figure de style, l'hyponomie implique un rapport d'inclusion unilatéral existant entre deux unités lexicales.

Il y a la lumière et il y a Osram [Publicité pour une marque d'ampoules électriques]

Quand on a besoin d'une voiture, on a besoin d'une Toyota

$\underline{8 \text { - L'utilisation de la marque comme un attribut }}$

Soyez très Dior - Jexfour, c'est jextraordinaire - Ils sont tous Morgan de moi 


\section{b) Figures jouant sur la sonorité des mots}

1 - La paronomase : La paronomase consiste à rapprocher dans une męme phrase des mots voisins par les sonorités. Cette figure est une des plus couramment utilisées dans la langue publicitaire, souvent même au détriment du sens du message.

Visa, ça va! -Entremont, c'est autrement bon-Du bon, du beau, Dubonnet-Du pain, du vin, du Boursin - Pas un pas sans Bata

2-L'allitération: L'allitération consiste à répéter une sonorité identique, souvent la consonne initiale.

Saucisse sèche sans savoir sécher - Sachez secouer ce Quick Shake

3 -Le calembour: Le calembour est un jeu de mots fondé sur la différence de sens entre deux mots qui se prononcent de manière identique ou rapproché.

L'âge du faire [Publicité pour une chaîne de magasins de bricolage - jeu de mots sur l'âge du fer] Transformez votre compte en conte de fées [Publicité pour une banque] Lego développe l'ego

\section{$\underline{B}$ - Les figures de construction :}

1 -L'inversion: L'inversion revient à renverser l'ordre grammatical et direct des mots (par exemple en plaçant le complément devant le sujet).

Mon Damart, je ne l'enlève qu'en présence d'Ariel [Partenariat multimarques entre un fabricant de vêtement (Damart) et un lessivier (Ariel). Dans le cas cité, l'inversion relève de la langue populaire et est très représentative du style "canaille chic » qu'affectionnent les publicitaires.] - La Tunisie, vous y irez avec plaisir

2-L'anacoluthe : L'anacoluthe consiste à introduire une rupture dans la construction grammaticale (par exemple ne supprimant les corrélatifs ou en substituant brusquement au sujet logique un sujet inattendu). L'emploi de l'anacoluthe est rare dans la langue publicitaire.

Pour les hommes qui aiment les femmes qui aiment les hommes [Publicité pour un parfum.]

3 - L'ellipse : Cette figure de style consiste à supprimer un ou plusieurs mots qui ne sont pas indispensable à la compréhension de la phrase. Elle est souvent usitée en publicité. L'omission du nom de la marque est une manière de montrer que celle-ci est tellement connue qu'il est inutile de la citer.

C'est mieux avec que sans [Pour une maque d'édulcorant.] - Les mamies ne lui disent pas merci [Pour la marque de produits laitiers Mamie Nova.]

4-L'anaphore: L'anaphore consiste à répéter le męme mot ou la męme tournure en vue de produire une gradation d'idées.

T'as le ticket chic, t'as le ticket choc [Publicité pour les transports en commun parisien. C'est frais, c'est aux fruits, c'est Banga [Publicité pour un jus de fruits]

5 - L'hypallage: L'hypallage utilsie une transposition grammaticale pour attribuer à certains mots des termes qui reviennent à d'autres par le sens. Cette figure est rarement utilisée en publicité.

Je prends la vie avec un sucre et demi

\section{C-Les figures de pensée :}

1 - L'antithèse : C'est une opposition de mots à mots d'idées à idées.

Taillefine, $0 \%$ de matière grasse, 100\% de plaisir

Achetez un portable, pas un jetable - Voyagez grand, dépensez petit 
2- Le chiasme : Assez rarement utilisé en publicité, le chiasme consiste à placer les éléments de deux groupes formant une antithèse dans l'ordre inverse de celui que laisse entendre la symétrie.

Plus je deviens mince, plus ils deviennent lourds [Publicité pour un édulcorant. La publicité joue aussi sur le sens figuré et familier de lourd qui signifient pressant : plus je deviens svelte, plus les garçons cherchent à me séduire]

Il y a de l'Urgo dans l'air, il y a de l'air dans Urgo [Publicité pour un pansement]

3 - La litote: La litote consiste à dire moins pour faire entendre plus.

Si vous n'avez pas encore une calculatrice Burroughs, nous vous offrons cette page blanche pour faire vos calculs - Dis papa, c'était quoi avant une voiture?

4-L'hyperbole: L'hyperbole est une exagération dans la description. C'est sans doute la figure la plus utilisée dans la publicité. On notera dans la langue publicitaire l'abus des préfixes super-, hyper- et méga-, souvent employés comme attribut ou en apposition.

Air France pour que le ciel soit le plus bel endroit de la terre - Elisabeth Arden, le plus grand secret de beauté de tous les temps - Omo lave toujours plus blanc-Garage X, des supers occasions [On notera l'adjonction d'un $s$ à super qui est contraire à toutes les règles mais qui correspond à un usage de la langue parlée (j'ai des super-z-amis)]

5-La prétérition: La prétérition est le refus simulé de dire quelque chose dont justement on va parler.

Quand on a 4 millions de lecteurs a-t-on encore besoin de faire de la pub?

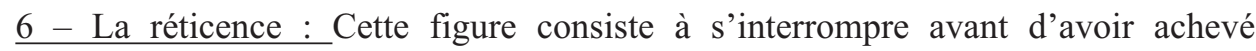
l'expression d'une pensée, tout en laissant entendre ce qu'on ne dit pas.

Connexion, des mecs qui en ont... [Publicité pour une société de travail temporaire]

7-Le paradoxe: Le paradoxe consiste à exprimer une opinion qui va contre la logique ou la manière habituelle de penser. Cette figure de style est fréquente en publicité.

Le Cognac Baron Otard, un luxe encore abordable

Boire Evian, c'est respirer à 3.000 mètres [Publicité pour une eau minérale]

Quand on regarde Canal+, au moins on n'est pas devant la télé [Publicité pour une chaîne de télévision] - La salle de bain qui tient dans une baignoire

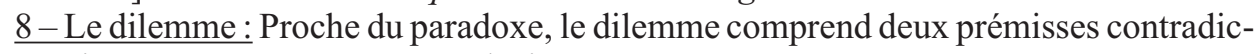
toires mais menant à une męme conclusion.

Comment concilier taille de guêpe et faim de loup? En mangeant Outspan!

Vous choisissez entre confort et beauté? Moi pas!

9-La tautologie : Considéré comme un vice logique, la tautologie revient à présenter comme ayant un sens différent, une proposition dont le prédicat ne dit rien de plus que le sujet. La tautologie est très souvent utilisée dans les slogans publicitaires car elle permet de jouer sur le prestige d'un produit.

Il n'y en a qu'une, c'est la Une [Publicité pour une chaîne de télévision]

Le cognac, c'est le cognac - Une Volkswagen est une Volkswagen - Seul Klaxon klaxonne

10 - Le détournement de proverbes, d'expressions familières ou de titre d'śvres connues: Ce procédé est devenu l'un des plus courant dans la langue publicitaire.

On a toujours besoin d'un petit pois chez soi [Détournement du proverbe « on a toujours besoin d'un plus petit que soi »]

Vivre de Woolite et d'eau fraîche [Détournement de l'expression « vivre d'amour et d'eau fraîche » au profit d'une marque de lessive]

On ne badine pas avec l'amour [Détournement du titre d'une pièce de Musset au profit d'un bijoutier] 


\section{Bibliographie}

[1] ADAM, J.-M. et BONHOMME, M.: L'argumentation publicitaire. Rhétorique de l'éloge et de la persuasion. Editions Armand Colin, Paris, 1997.

[2] AMOSSY, R. et alii: Stéréotypes et clichés. Langues, discours et société. Editions Armand Colin, Paris, 1977.

[3] BROCHAND, B. et LENDREVIE, J.: Le Publicitor. Editions Dalloz, Paris, 1989.

[4] BRUNE, F.: L'impérialisme publicitaire in Le Monde diplomatique. janvier 1986.

[5] DAYAN, A.: La Publicité. Presses universitaires de France, collection «Que sais-je?», Paris, 1995.

[6] DURAND, J.: Rhétorique et image publicitaire in Communications $n^{\circ} 15$, janvier 1970, p. 70-95.

[7] GRUNIG, B.: Les mots de la publicité. Paris, Editions du CNRS, 1998.

[8] SUBERVILLE, J.: Théorie de l'art et des genres littéraires. Editions de l'Ecole, Paris, 1969. 


\title{
Rétorika reklamy v současné francouzštině
}

\section{Pierre Brouland}

\begin{abstract}
Abstrakt
Reklama, která je neoddělitelnou součástí globalizace, se stala významným prostředkem šíření jazyka, at’ už psaného či mluveného. Ačkoliv je reklama považována za faktor přispívající k ochuzování jazyka, využívá hojně klasické rétoriky. Na základě příkladů podává článek přehled nejdůležitějších stylistických obratů používaných při vytváření reklamních sloganů a sdělení ve francouzštině. Z tohoto zkoumání vyplývá, že převažují slovní obraty na úkor obratů konstrukčních a myšlenkových.
\end{abstract}

Klíčová slova: rétorika; reklama; francouzština.

\section{Rhétorique de la publicité dans le français contemporain}

\begin{abstract}
Elément inséparable de la globalisation, la publicité est devenue un véhicule important de la langue, qu'elle soit écrite ou parlée. Bien que souvent considérée comme un facteur d'appauvrissemnt de la langue, la publicité utilise cependant abondamment les figures de la rhétorique classique. L'article se propose de recenser, à l'aide d'exemples, les principales figures de style utilisées dans la rédaction des slogans et des messages publicitaires en français. Il apparaît au terme de cette étude que ce sont les figures de mots qui dominent au détriment des figures de construction ou de pensée.
\end{abstract}

Key words: rhétorique; publicité; français. 